\title{
Comparison between two carbonyl measurement methods in the atmosphere
}

\author{
C.P. Ferrari ${ }^{1,2, *, * *}$, R. Durand-Jolibois ${ }^{3}$, P. Carlier ${ }^{3}$, V. Jacob ${ }^{1}$, A. Roche ${ }^{1}$, P. Foster ${ }^{1}$ and P. Fresnet ${ }^{3}$ \\ ${ }^{1}$ Groupe de Recherche sur l'Environnement et la Chimie Appliquée, Université Joseph Fourier, I.U.T de Chimie, \\ 39-41 boulevard Gambetta, 38000 Grenoble, France \\ ${ }^{2}$ Institut des Sciences et Techniques de Grenoble, Université Joseph Fourier, 28 avenue Benoît Frachon, \\ BP. 53, 38041 Grenoble, France \\ ${ }^{3}$ Laboratoire Interuniversitaire des Systèmes Atmosphériques, associé au CNRS, Centre Multidisciplinaire, \\ Universités Paris VII et Paris XII, 61 avenue du General De Gaulle, 94010 Creteil Cedex, France
}

\begin{abstract}
Two atmospheric aldehyde sampling techniques, the impinger method in which aldehydes are trapped in a 2,4-dinitrophenylhydrazine acidified acetonitrile solution, and the method in which aldehydes are captured in 2,4-dinitrophenylhydrazine acidified coated cartridges commercialised by the WATERS ${ }^{\circledR}$, were compared for blank values, sample preservation, ozone action, and water influence. The two methods were tested in a Paris atmosphere and the influence of a KI ozone scrubber has been evaluated. Except for acetaldehyde and benzaldehyde, the two techniques do not give coherent results. When no ozone scrubber is used, the cartridge technique gives systematically lower values. Bad correlation has been obtained between data with scrubber and data without scrubber for the impinger technique except for acetaldehyde. For the cartridge technique, the correlation is better for all the aldehydes but higher values are found when a scrubber is used, except for formaldehyde. Ozone action leads to 2,4-dinitrophenylhydrazone destruction, but also to formaldehyde 2,4-dinitrophenylhydrazone formation by reaction between airborne volatile organic compounds and ozone on the cartridge surfaces.
\end{abstract}

Key words. Aldéhydes - ketones - impinger - cartridge - ozone - field measurement.

\section{Introduction}

Carbonyl compounds play a major role in troposphere physical chemistry [1-3]. They can be directly emitted in the atmosphere by mobile sources and vegetation [4-5]. They can originated from organic compound oxydation by $\mathrm{OH}$ radical in the troposphere [6]. As those compounds are potentially photolysable, they constitute an additional source of free radicals which are mainly significant during the early morning [7-8]. Thus, aldehyde measurements in the atmospheric environment are especially interesting for atmospheric photochemistry studies [9-10].

However, the atmospheric measurement of these products is not without difficulties. Different techniques described in details elsewhere [11-16] have been tested. Various sampling methods have been tested but in recent years, only the 2,4dinitrophenylhydrazine method followed by HPLC analysis of the formed derivates has remained [17-18]. This chromatographic analysis gives simultaneously the lowest threshold values and a separation analysis of each component. The other techniques are of little more than historical interest. They can however be considered for short studies since they are easier and less expensive to set up. In the last few years, new methods have been proposed but none have been widely adopted. The chromotropic acid method has been used for formaldehyde determination [19]. It is only suitable for highly polluted media and requires long sampling times. A method with 3-methyl-2-benzothiazolone is sensitive but the overall value is wrong because the absorption coefficient varies from one compound to another [20]. Chemical derivatization with 2,4-dinitrophenylhydrazine, HPLC separation of formed 2,4-dinitrophenylhydrazones and UV detection is still currently employed but aldehydes from pentanal to undecanal can be easily analysed by gas chromatography [21]. Various used protocols differ only by their derivatization and capture techniques. These techniques are of two main types, those with impingers, and those with coated cartridges. The comparison of the data obtained by these two methods is not easy. In the following study, we try to answer to this difficulty by comparing these two methods performance on the basis of laboratory tests and atmospheric measurements, under the same conditions: i.e. flow rate: $1 \mathrm{~L} / \mathrm{min}$, sampling time: 2 hours. The influence of ozone and water has been tested for the two methods.

\footnotetext{
* Correspondence and reprints.

** Now at this address: Laboratoire de Glaciologie et Géophysique de l'Environnement du CNRS, associé à l'Université Joseph Fourier, 54 rue Molière, BP. 96,38402 SaintMartin-d'Heres Cedex, France.

Received June 23, 1998; revised October 8, 1998; accepted October 13, 1998.
} 


\section{Original articles}

\section{Experimental methods}

\section{Impinger method}

In the impinger method the aldehydes were preconcentrated and derivatized in washer flasks containing $20 \mathrm{~mL}$ of 2,4dinitrophenylhydrazine at $0.12 \mathrm{~g} / \mathrm{L}$ in acetonitrile (HPLC quality) acidified by $\mathrm{H}_{2} \mathrm{SO}_{4}(400 \mu \mathrm{L} / \mathrm{L})$. During the sampling ( $1 \mathrm{~L} / \mathrm{min}$ for 2 hours), solutions were cooled to 2 to $4{ }^{\circ} \mathrm{C}$ in order to minimise solvent evaporation. The solutions were analysed by HPLC at least 2 hours after again reaching ambient temperature. The 2,4-dinitrophenylhydrazine used was recrystallized three times in acetonitrile (HPLC quality) under pure nitrogen. The trapping solution was only acidified just before sampling.

\section{Coated cartridges method}

The tested cartridges contain $0.35 \mathrm{~g}$ of coated silica (particle size from 55 to $105 \mu \mathrm{m}$ ) with $1 \mathrm{mg}$ of 2,4-dinitrophenylhydrazine available under commercial label "SepPack Cartridges DNPH Silica” (Waters ${ }^{\circledR}$ ). 2,4-dinitrophenylhydrazone was eluted from the cartridge with $3 \mathrm{~mL}$ of acetonitrile (HPLC quality) in a pure nitrogen flushed chamber [18]. The sample was adjusted at $5 \mathrm{~mL}$ with acetonitrile for HPLC analysis.

\section{Common HPLC Analysis conditions}

- Column $\mathrm{C}_{18}$ (Shandon), $(250 \mathrm{~mm} \times 4.6 \mathrm{~mm} ; 5 \mu \mathrm{m})$.

- Loop volume: $20 \mu \mathrm{L}$.

- Eluant: $1 \mathrm{~mL} / \mathrm{min}$ (water/acetonitrile, the solvent gradient is indicated in Tab. I).

- HPLC: Applied Biosystems 400.

- Detection: UV visible absorption at $360 \mathrm{~nm}$ (Applied Biosystems 783A detector).

- Carbonyls analysed: Formaldehyde, Acetaldehyde, Propanal, Acetone, Benzaldehyde, Butanal, Cyclohexanone.

\section{Blanks and detection limits}

In order to estimate the detection limits for the various aldehydes studied, we measured blank values of each one.

Table I. Liquid chromatography gradient program.

\begin{tabular}{cl}
\hline Time $($ min $)$ & Mobile phase composition \\
\hline 0 & acetonitrile/water $(55 / 45)$ \\
10 & acetonitrile/water $(55 / 45)$ \\
20 & acetonitrile/water $(70 / 30)$ \\
25 & acetonitrile/water $(65 / 35)$ \\
30 & acetonitrile/water $(55 / 45)$ \\
35 & acetonitrile/water $(55 / 45)$ \\
\hline
\end{tabular}

We must note that an essential difference exists between these two methods. In the impinger method, the blank is measured on a very small fraction of the trapping solution. This blank is a "true blank" (to be opposed to an estimated blank: see blank for the cartridges). Without sampling mistakes, blank uncertainty is only due to noise and analytical method repetability. The experiment shows that the noise creates an uncertainty of about $0.05 \mathrm{ppbv}$ (three times the noise measured crest to crest) and the analytical repetability is better than $5 \%$. For instance, a blank (the worst never recorded) is given in figure 1.

In this chromatogram, only formaldehyde, acetaldehyde and acetone have got significant contamination blank peaks. Detection limit is given out by the formula:

$$
\Delta_{C}(\mathrm{ppbv})=0.05+5 \% C_{\text {blank }} .
$$

These detection limits are for the different aldehydes given as follow:

$$
\begin{aligned}
\Delta C & =0.1 \mathrm{ppbv} \text { for formaldehyde } \\
\Delta C & =0.07 \mathrm{ppbv} \text { for acetaldehyde } \\
\Delta C & =0.05 \mathrm{ppbv} \text { for other aldehydes. }
\end{aligned}
$$

For the cartridges, blank is measured by testing 5 cartridges in a box which contains 20 cartridges. It is an estimated blank. The estimated value is the mean of five determinations $(\mu)$, additional uncertainties due to sampling random have been fixed at three times the standard deviation $(\sigma)$. The detection limit is then:

$$
\Delta C(\mathrm{ppbv})=0.05+5 \% \mu+3 \sigma .
$$

Our study was carried out on seven sets and the results are presented in table II (data corresponding to a 120 liters air sample).

The main conclusion is that the inner dispersion in the set is so high that we can't expect reliable evaluation by testing only one cartridge because of the importance of the term $3 \sigma$. Secondly, it appears that different sets can be very heterogeneous and to be sure that we have the correct

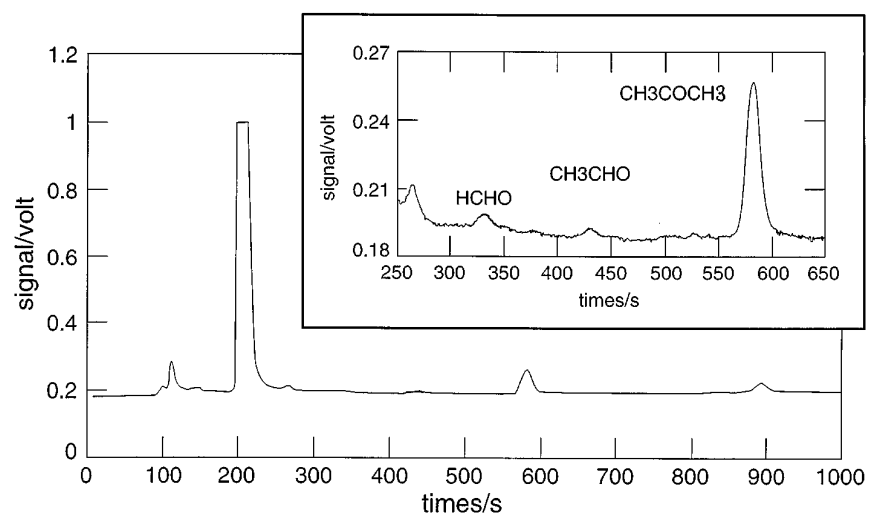

Fig. 1. Impinger technique blank. 
detection limit for the viewed study, it is suitable to test before sampling received cartridge sets. For the best ones, detection limit is a little higher than the one obtained with impinger method.

\section{Sample stability}

Impingers: A sample was kept at ambient temperature and analysed over 5 days at regular intervals. During the first thirty-six hours, no remarkable changes were observed. Afterwards, a slow decrease of the 2,4-dinitrophenylhydrazone peaks (loss of 10 to $15 \%$ after seventy-two hours) was recorded and non identified new peaks were observed.

Cartridges: Formaldehyde, acetaldehyde and benzaldehyde were injected in a $2 \mathrm{~m}^{3}$ chamber [22] with the following respective concentrations: $26.7 \mathrm{ppbv}, 14.6 \mathrm{ppbv}$ and 3.4 ppbv. Twelve cartridges, originated from the same set, were sampled with a $1 \mathrm{~L} / \mathrm{min}$ sampling flow rate and three minutes sampling time. The concentration of carbonyl in the chamber was stable for about 3 hours. Those cartridges were stored at $4{ }^{\circ} \mathrm{C}$ and analysed over ten days. During the first seven days, no diminution of the values was noted. Afterwards, a decrease is observed. The elution of sampled cartridges must be done in less than a week. After this time, an increase of the acetone 2,4-dinitrophenylhydrazone is observed probably due to sample contamination or other 2,4dinitrophenylhydrazone destruction.

\section{Interference with ozone}

In the first cartridges tested in 1984, significant aldehyde quantities (mainly formaldehyde) were generated explaining why abnormal high values were systematically found. This creation is related to volatile organic compounds (caught by the cartridges) that are oxidized by ozone present in air. The use of an ozone scrubber i.e. precartridges with either KI or $\left(\mathrm{FeSO}_{4}, 7 \mathrm{H}_{2} \mathrm{O}\right)$ was recommended.

\section{Aldehyde production test in preconcentration system}

Two experiments have been conducted in order to evaluate the impact of ozone on aldehyde production in impingers and cartridges. The first experiment consisted in introducing in the impingers and cartridges known quantities of 3 hydrocarbons: (hexene-1: 1.7 ppbv, $n$-hexane: 1.7 ppbv, toluene: $1.8 \mathrm{ppbv})$. These three hydrocarbons were chosen as they can represent the three principal hydrocarbon chemical families: alkane, alkene and aromatic. These three families have a different reactivity with ozone. $n$-hexane and $n$-hexene and were chosen preferentially to pentane and pentene as they are less volatile, and so are easier to manipulate. Benzene was not used as it is known to be a carcinogenic agent. They were introduced by injecting $0.7-0.8 \mu \mathrm{g}$ of each compound from a diluted $\mathrm{CCl}_{4}$ solution directly in the impinger and upstream the cartridge. Both impingers and cartridges were flushed with a 120 liters ozoned air at $107 \mu \mathrm{g} / \mathrm{m}^{3}$ at $1 \mathrm{~L} / \mathrm{min}$ flow rate produced by an ozone generator DZ 1000-L KAUFMANN. Ozone concentration was measured with a 1003H-Environnement S.A.-Licence DASIBI. The second experiment consisted in flushing impingers and cartridges (without hydrocarbon) with ozone at $107 \mu \mathrm{g} / \mathrm{m}^{3}$. The last experiment corresponded to impingers and cartridges with no treatment (no hydrocarbons and no ozone) but flushed with air cleaned with silica gel, active charcoal, lime soda and $4 \AA$ molecular sieve. The samples were analysed as described in details before. Experiences were triplicated. The results are given in figures 2 and 3 .

Impinger: Formaldehyde and $n$-propanal are not generated by hydrocarbons and ozone reactions as formaldehyde and n-propanal hydrazone levels are not enhanced (Fig. 2). For acetaldehyde and benzaldehyde, we observe important differences for each test. For both derivates, the action of ozone led to enhanced hydrazone levels. This increase is largely magnified when hydrocarbons are introduced.

For $n$-butanal and acroleine/acetone, we observe a significant increase of these compound derivates when ozone is flushed in the impinger. When hydrocarbons are introduced, the levels are the same for acroleine/acetone, and weakly

Table II. Blank values for different cartridge sets (evaluated for a 120 liters air sample).

\begin{tabular}{|c|c|c|c|c|c|c|}
\hline Set & $\begin{array}{c}\mu\left(\mathrm{CH}_{2} \mathrm{O}\right) \\
(\mathrm{ppbv})\end{array}$ & $\begin{array}{c}\sigma\left(\mathrm{CH}_{2} \mathrm{O}\right) \\
(p p b v)\end{array}$ & $\begin{array}{l}\text { Detection limit } \\
(p p b v)\end{array}$ & $\begin{array}{c}\mu\left(\mathrm{CH}_{3} \mathrm{CHO}\right) \\
(p p b v)\end{array}$ & $\begin{array}{c}\sigma\left(\mathrm{CH}_{3} \mathrm{CHO}\right) \\
(p p b v)\end{array}$ & $\begin{array}{l}\text { Detection limit } \\
(p p b v)\end{array}$ \\
\hline P 4132 A3 & 0.48 & 0.06 & 0.25 & 0.37 & 0.04 & 0.19 \\
\hline P 4108 A1 & 0.40 & 0.03 & 0.25 & 0.23 & 0.03 & 0.15 \\
\hline P 2046 A2 & 0.58 & 0.56 & 1.76 & 1.78 & 0.11 & 0.47 \\
\hline P 3310 A2 & 1.55 & 0.42 & 1.39 & 0.84 & 0.10 & 0.39 \\
\hline T 4341 G5 & 0.16 & 0.02 & 0.12 & 0.18 & 0.02 & 0.10 \\
\hline T 5003 G3 & 0.16 & 0.06 & 0.24 & 0.12 & 0.03 & 0.15 \\
\hline T 5255 G2 & 0.87 & 0.40 & 1.30 & 1.10 & 0.03 & 0.20 \\
\hline
\end{tabular}




\section{Original articles}

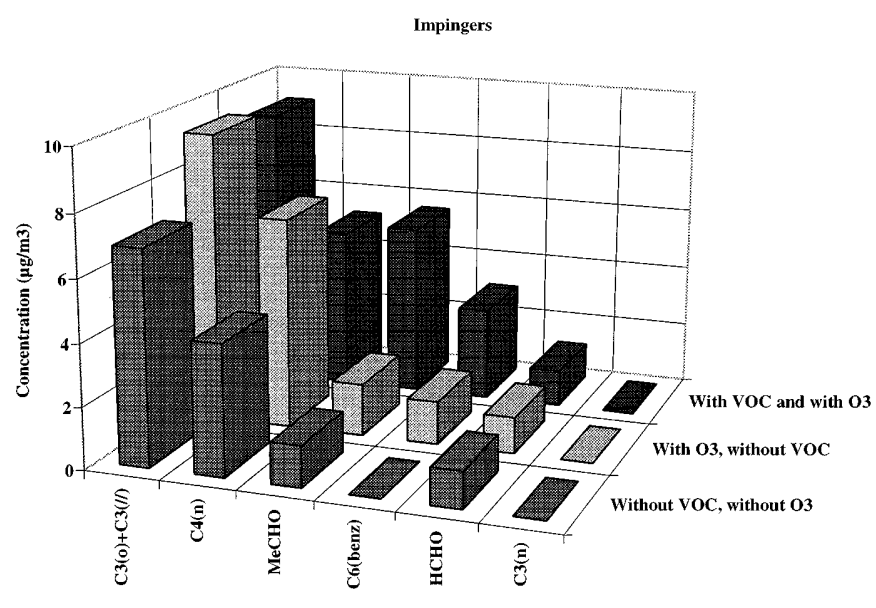

Fig. 2. Aldehyde creation in impinger under ozoned air action with and without VOC $\left(\mathrm{C}_{3}(\mathrm{o})+\mathrm{C}_{3}(/ /)\right.$ : acetone + acroleine; HCHO: formaldehyde; $\mathrm{MeCHO}$ : acetaldehyde; $\mathrm{C}_{3}(n)$ : $n$-propanal; $\mathrm{C}_{4}(n)$ : $n$-butanal; $\mathrm{C}_{6}($ benz): benzaldehyde).

reduced for $n$-butanal. Reactions between hydrocarbons and ozone generated benzaldehyde and acetaldehyde in impingers and led to the in-situ formation of benzaldehyde and acetaldehyde hydrazone.

Cartridge: For formaldehyde and $n$-propanal, we observe an increase in hydrazone levels when an ozoned air is flushed throught the cartridge. Levels are strongly enhanced for formaldehyde (but lower for $n$-propanal) when hydrocarbons are introduced and ozone is flushed. It is like if, formaldehyde and n-propanal derivates strongly originated from the reactivity between ozone and hydrocarbons. For other hydrazone (benzaldehyde, $n$-butanal, acetaldehyde and acroleine/acetone), the levels obtained with hydrocarbons and ozone are lower than when only ozone is flushed. These derivates do not originate from hydrocarbons and ozone reactivity.

\section{2,4-dinitrophenylhydrazone destruction test}

Impingers: Solutions of 2,4-dinitrophenylhydrazones (formaldehyde, acetaldehyde, $n$-propanal and benzaldehyde) in acetonitrile (concentrations of about $\sim 30 \mu \mathrm{g} / \mathrm{L}$ ) are flushed with a 120 liters $50 \mathrm{ppbv}$ ozoned air at $1 \mathrm{~L} / \mathrm{min}$ flow rate. No effect has been observed. For higher ozone concentrations (> $140 \mathrm{ppbv}$ ), we can note that new peaks appear either solution has got 2,4-dinitrophenylhydrazones or not. These peaks come from 2,4-dinitrophenylhydrazine as it is the major compound. This has been observed by Arnst and Tejada [23], and other authors [24-25].

Cartridges: Formaldehyde, acetaldehyde, benzaldehyde and acetone are injected in a $2 \mathrm{~m}^{3}$ chamber [21] with the following respective concentrations: $15.7 \mathrm{ppbv}, 8.7 \mathrm{ppbv}, 4.0$ ppbv and 4.4 ppbv. Six cartridges are sampled with a sampling flow rate of $1 \mathrm{~L} / \mathrm{min}$ and a sampling time of $3 \mathrm{~min}$ utes. Three cartridges are flushed with 120 liters ozoned air

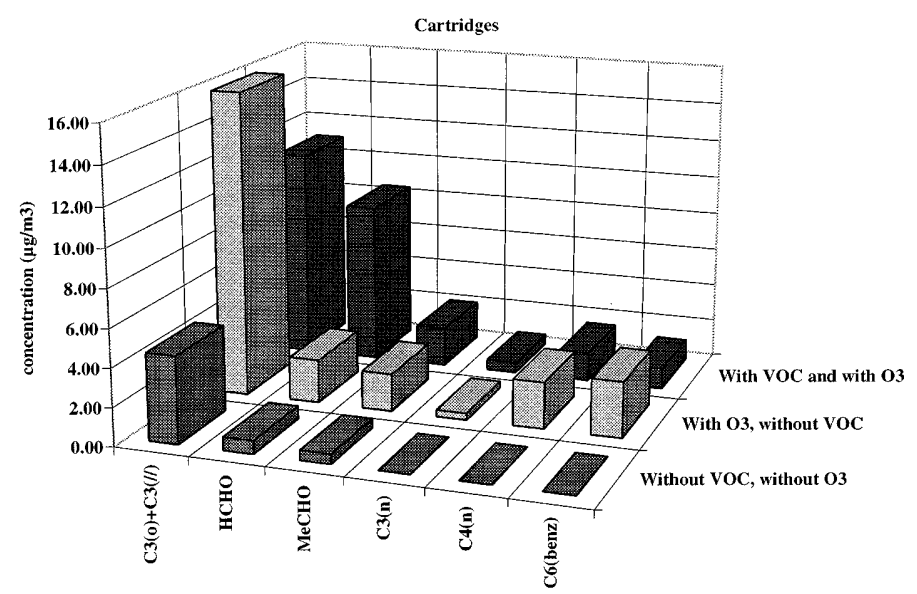

Fig. 3. Aldehyde creation in cartridge under ozoned air action with and without VOC's $\left(\mathrm{C}_{3}(\mathrm{o})+\mathrm{C}_{3}(/ /)\right.$ : acetone + acroleine; HCHO: formaldehyde; MeCHO: acetaldehyde; $\mathrm{C}_{3}(n)$ : $n$-propanal; $\mathrm{C}_{4}(n)$ : $n$-butanal; $\mathrm{C}_{6}($ benz): benzaldehyde).

(1 L/min) at $150 \mathrm{ppbv}$ air and the last three ones are flushed with 120 liters air zero (synthetic air) at $1 \mathrm{~L} / \mathrm{min}$. The cartridges are analysed and the formaldehyde, acetaldehyde, benzaldehyde and acetone concentrations are presented in table III.

The 2,4-dinitrophenylhydrazones are transformed by ozone action at various rates. Formaldehyde and acetaldehyde hydrazone are the most affected by these transformations. The uncertainty on the 2,4-dinitrophenylhydrazone transformation part is the most important for formaldehyde indicating various and complexes destruction mechanisms. Benzaldehyde 2,4-dinitrophenylhydrazone seems to be less reactive regarding to ozone action than aliphatic aldehydes. Acetone 2,4-dinitrophenylhydrazone levels are strongly enhanced during the ozone action. Two unknown 2,4-dinitrophenylhydrazones are generated during the ozone treatment, as indicated on the chromatograms presented in figure 4 .

\section{Humidity influence}

Hydrazones hydrolysis has been followed by adding known water quantities to a trapping acetonitrile solution

Table III. Ozone action on 2,4-dinitrophenylhydrazone derivates in coated cartridges.

\begin{tabular}{lcccc}
\hline $\begin{array}{c}\text { Formaldehyde } \\
(p p b v)^{*}\end{array}$ & $\begin{array}{c}\text { Acetaldehyde } \\
(p p b v)^{*}\end{array}$ & $\begin{array}{c}\text { Benzaldehyde } \\
(p p b v)^{*}\end{array}$ & $\begin{array}{c}\text { Acetone } \\
(p p b v)^{*}\end{array}$ \\
\hline Air zero & $15.7 \pm 0.4$ & $8.7 \pm 0.1$ & $2.0 \pm 0.1$ & $4.4 \pm 0.4$ \\
Ozoned air $7.8 \pm 4.3$ & $3.6 \pm 1.3$ & $1.5 \pm 0.4$ & $12.2 \pm 0.1$ \\
\hline
\end{tabular}

* Evaluated for a 120 liters air sample. 

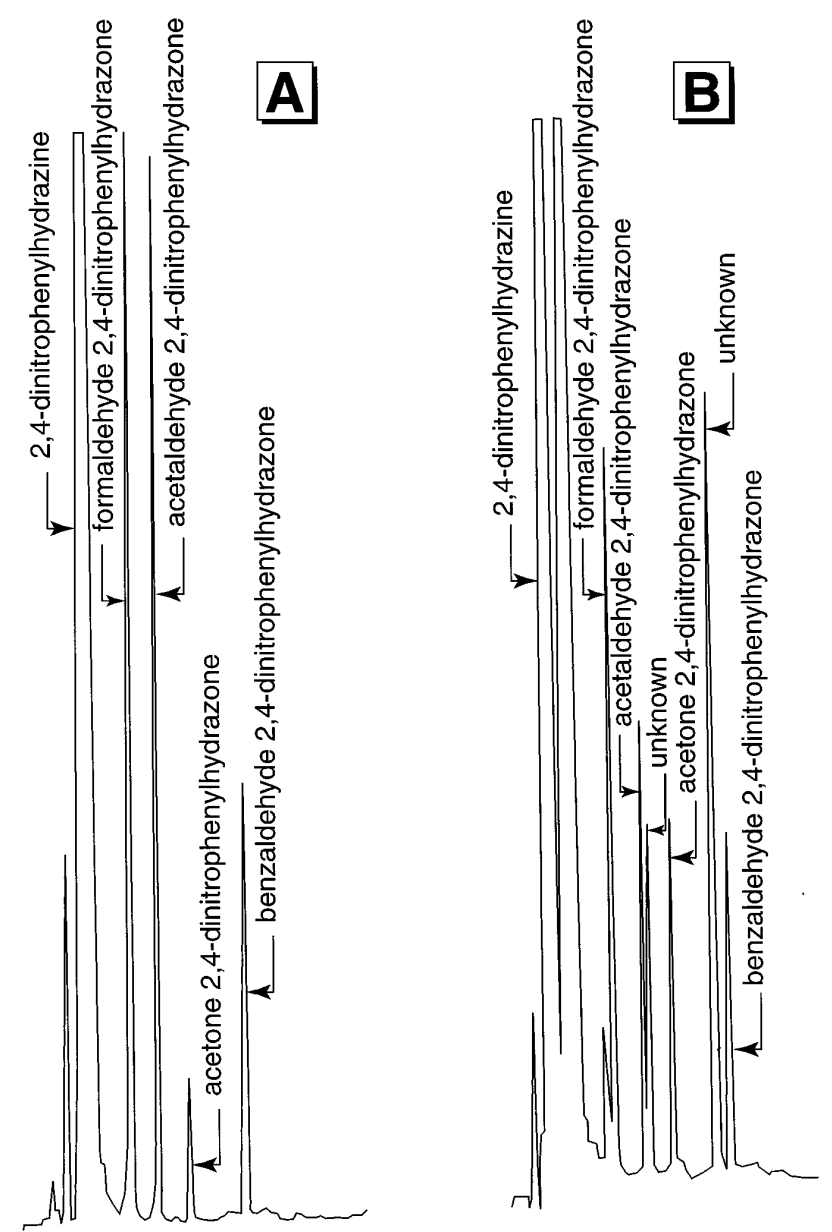

Fig. 4. Effect of ozone on 2,4-dinitrophenylhydrazone. A: cartridge containing formaldehyde, $15.7 \mathrm{ppbv}$; acetaldehyde, $8.7 \mathrm{ppbv}$; benzaldehyde, $2.0 \mathrm{ppbv}$; acetone, $4.4 \mathrm{ppbv}$, flushed with zero ozoned air. B: cartridge A flushed with $120 \mathrm{~L} 150$ ppbv ozoned air. containing known concentrations of different hydrazones (Fig. 5). It is clear that saturated or aromatic aldehyde hydrazone are not affected by water influence. On the contrary, acetone hydrazone is strongly hydrolysed when water proportion is important (up to $10 \%$ ). It has been shown that during field tests, concentrations about $10 \%$ can be obtained. During field measurements, smaller peaks have been observed for acetone when no water trap is used indicating a possible hydrolysis of the ketone's hydrazone [20]. For the cartridge technique, Foster et al. [15] have demonstrated that ketone derivatives (especially propanone and butanone) are transformed in 2,4-dinitrophenylhydrazine and free ketone in presence of water in an acidic solution.

\section{Field applications}

A comparison was made from October, 5th, 1994 at 10.00 a.m. (legal hour $=\mathrm{GMT}+1$ hour) to October, 7th, 1994 at 14.00 p.m. at Créteil campus (13 km SE away from Paris). Four samples have been simultaneously conducted in similar conditions of flow rate $(1 \mathrm{~L} / \mathrm{min})$ and sampling time ( 2 hours), two with impingers, and two with cartridges with or without ozone "scrubber" (precartridge of $0.66 \mathrm{~g} \mathrm{KI}$ prepared in the laboratory (see [27]). Results are given in table IV. In order to compare these two techniques, results are presented in figure 6. For each aldehyde, three comparisons have been made. The comparison has reached on the influence of the scrubber for impinger and cartridge. The last comparison was between cartridge and impinger directly.

\section{Formaldehyde}

For the impinger technique, a bad correlation has been obtained between data with scrubber and data without scrubber $\left(r^{2}=0.13\right)$. The use of an ozone scrubber gives in

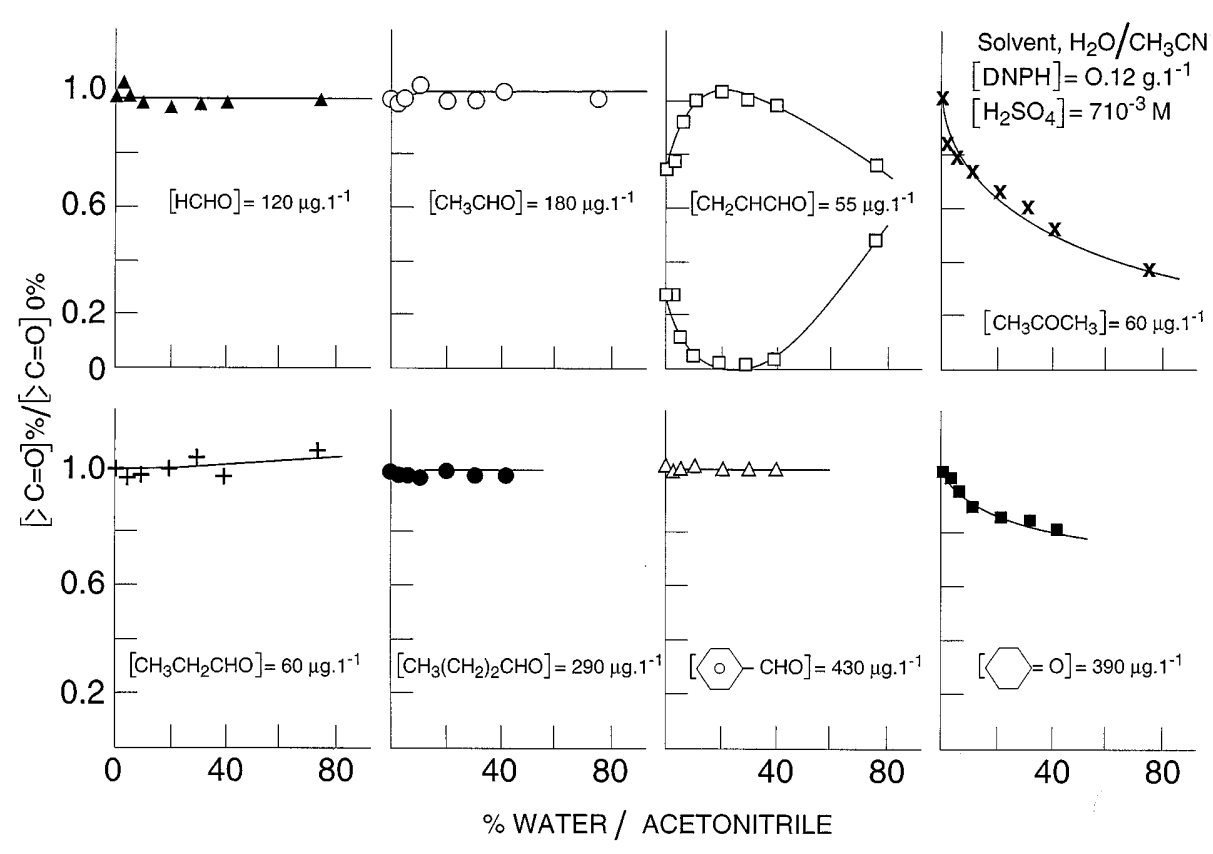

Fig. 5. Hydrazone hydrolysis tests as a function of water percentage in the acetonitrile solution. It can be shown that aldehyde hydrazones (aliphatic and aromatic) are not affected by humidity. The two tested ketones (propanone and cyclohexanone) are on the contrary totally hydrolysed. Acroleine gives two chromatographic peaks (probably the two conformers). The area ratio of those two peaks depends on humidity but the areas sum is conservative. 


\section{Original articles}

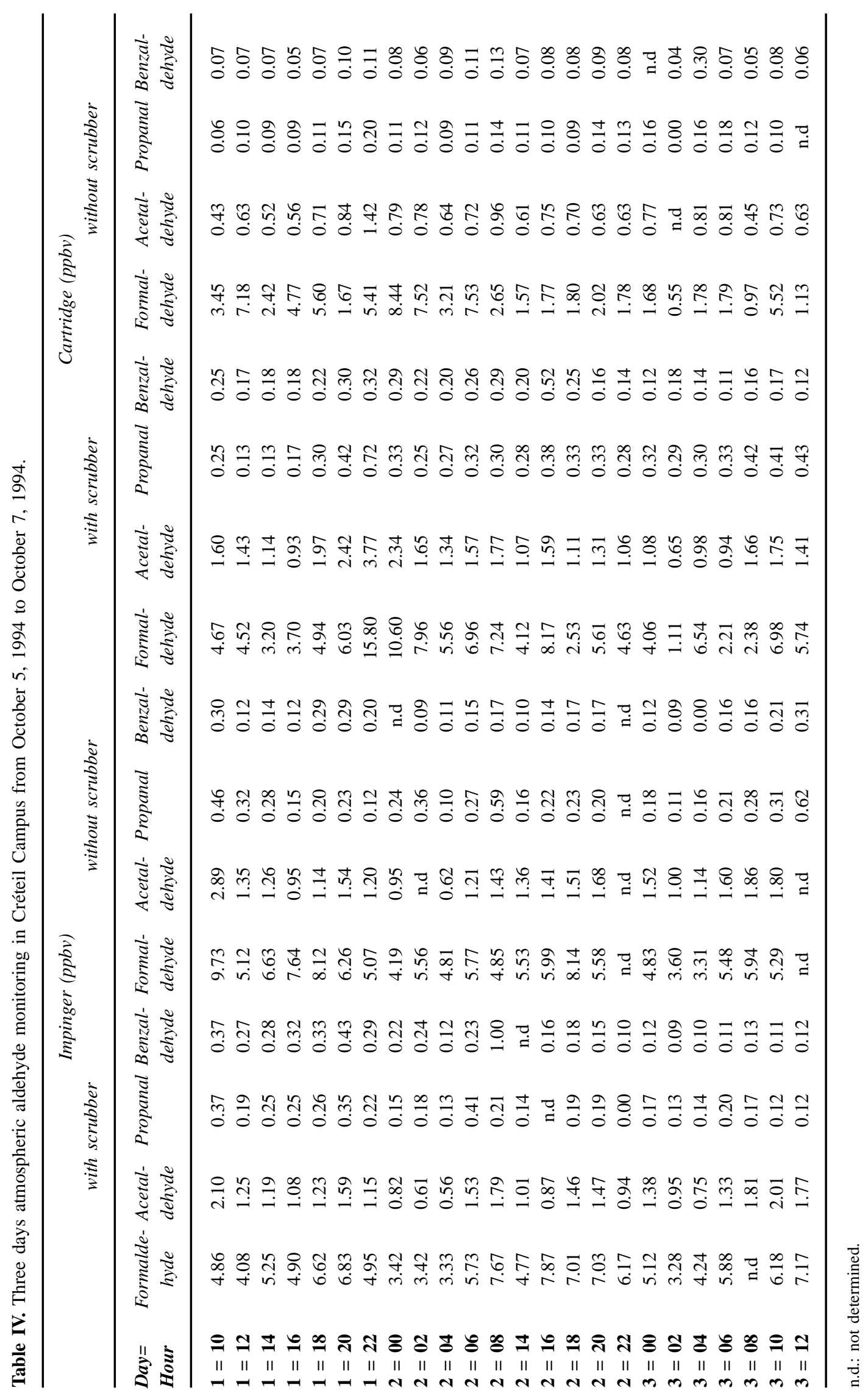




\section{Original articles}

\section{FORMALDEHYDE}
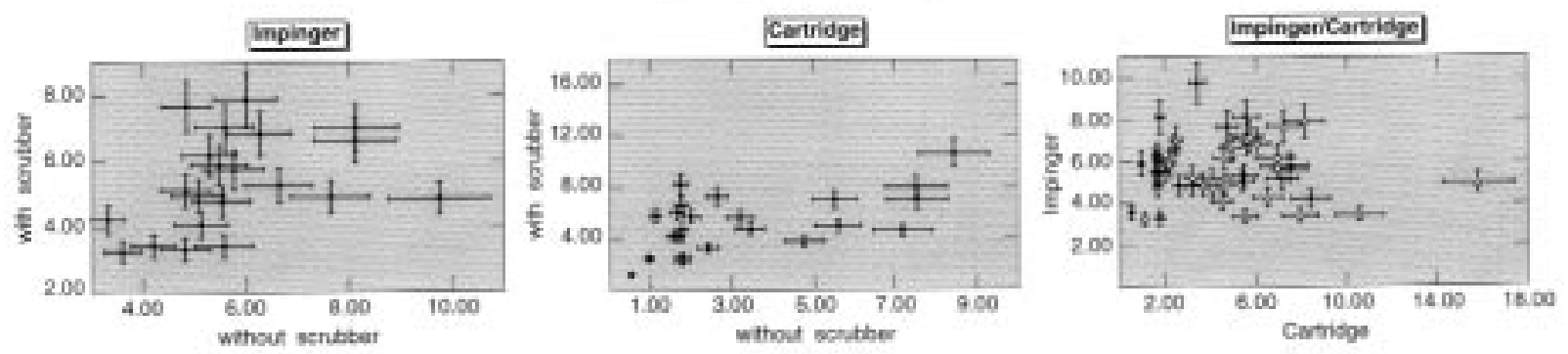

\section{ACETALDEHYDE}
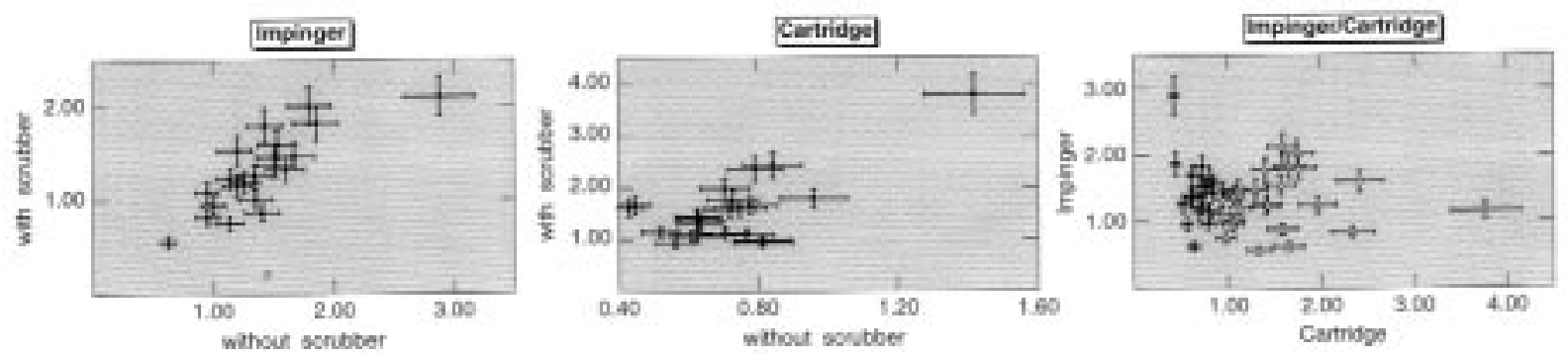

Fig. 6. Comparison of two aldehyde sampling techniques for formaldehyde and acetaldehyde: cartridge and impinger. Influence of an ozone scrubber on aldehyde measurement. The first column compares the use of an ozone scrubber for the impinger technique. The middle column compares the use of an ozone scrubber for the cartridge technique. The last column compares the two techniques. ( $\mathrm{n}$ : data without scrubber; $\triangle$ : data with scrubber).

\section{PROPIONALDEHYDE}
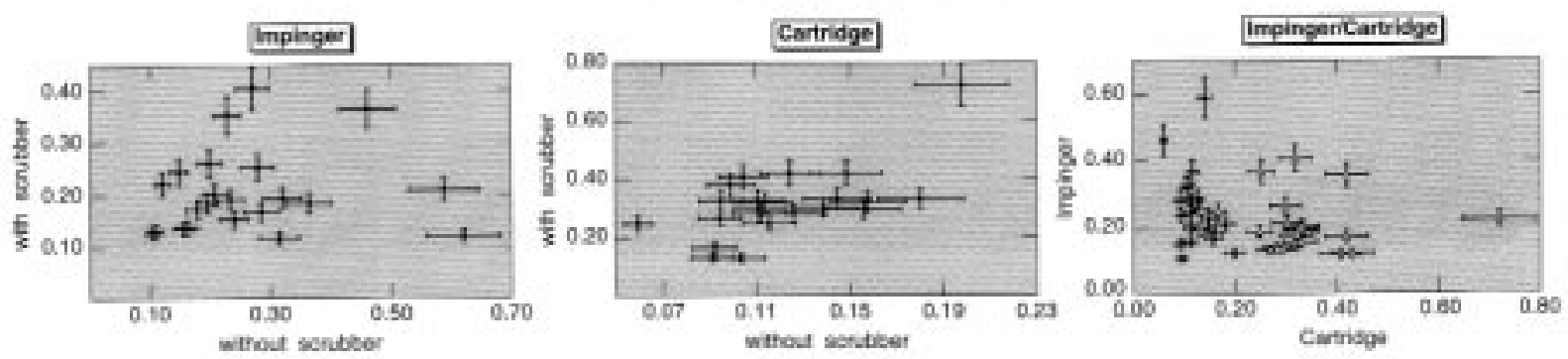

\section{BENZALDEHYDE}
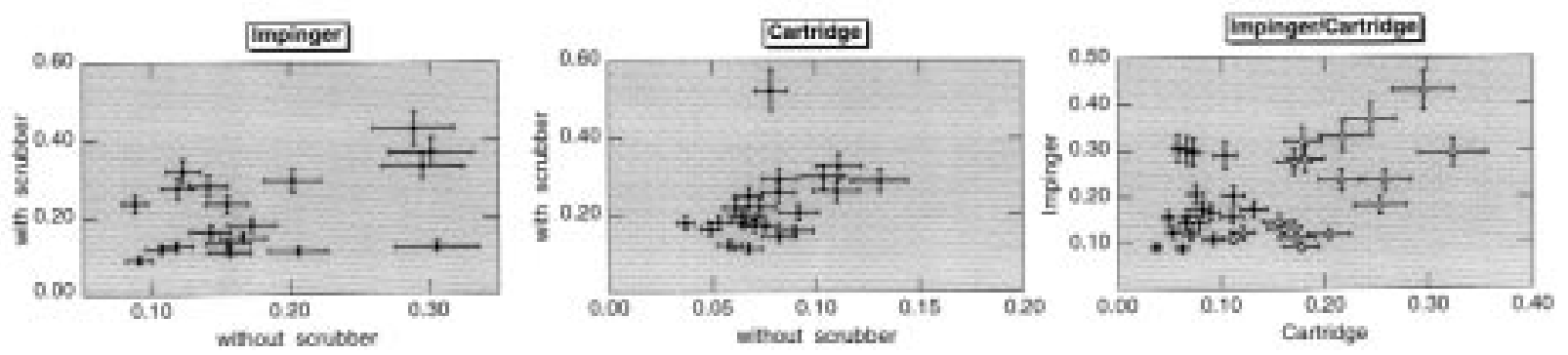

Fig. 7. Comparison of two aldehyde sampling techniques for propionaldehyde and benzaldehyde: cartridge and impinger. Influence of an ozone scrubber on aldehyde measurement. The first column compares the use of an ozone scrubber for the impinger technique. The middle column compares the use of an ozone scrubber for the cartridge technique. The last column compares the two techniques. ( $\mathrm{n}$ : data without scrubber; $\triangle$ : data with scrubber). 


\section{Original articles}

general lower values. For the cartridge technique, the correlation between data with scrubber and data without scrubber is also bad $\left(r^{2}=0.26\right)$. Contrary to the impinger technique, the use of an ozone scrubber gives higher values. The comparison between data from cartridge and data from impinger gives two observations. When an ozone scrubber is used for both sampling technique, values are higher for impinger (from 4 to $11 \mathrm{ppbv}$ ) and lower for cartridge (1.4 to $4 \mathrm{ppbv}$ ). These observations are not in agreement with those obtained by Lipari and Swarin (1985) [28]. During field sampling (flow rate of $1 \mathrm{~L} / \mathrm{min}$ and 2 hours sampling time) in Warren, MI (USA), a very good correlation was obtained between both techniques. Ratio cartridge/impinger ranges between $0.89-1.31$. The cartridges tested were prepared by the authors: they were packed with $60-80$ mesh Florisil and coated with a $2 \mathrm{mg} / \mathrm{mL}$ DNPH solution in dichloromethane. No ozone data was given. In this study, tests were made only on formaldehyde.

\section{Acetaldehyde}

For the impinger technique, we can notice a better correlation between data with scrubber and data without scrubber $\left(r^{2}=0.65\right)$. Values without scrubber appear to be higher than with scrubber. For cartridges, the correlation is bad $\left(r^{2}=\right.$ 0.50 ) but values with scrubber are about two times higher than those without scrubber. The comparison between impinger and cartridge techniques indicates that when no ozone scrubber is used, values for impinger are higher and when an ozone scrubber is used values appear a little higher for cartridge.

\section{Propionaldehyde}

For impinger, no correlation is observed between data with scrubber and data without scrubber $\left(r^{2}=0.01\right)$. For the cartridge sampling technique, the correlation is better but bad $\left(r^{2}=0.26\right)$, and values with scrubber are about three times higher. When no scrubber is used, values appear to be very low for cartridge $(\sim 0.25 \mathrm{ppbv})$. Comparison between cartridge and impinger techniques using an ozone scrubber indicate more correlated data.

\section{Benzaldehyde}

No correlation $\left(r^{2}=0.04\right)$ has been obtained between data with scrubber and data without scrubber. On the contrary a better correlation is observed for the cartridge technique (but still bad; $r^{2}=0.20$ ), and values are about three times higher with scrubber. Concerning the two sampling techniques, it appears that when no ozone scrubber is used, values for cartridges are very low and do not exceed 0.6 ppbv while values for impinger are included between 0.5 to $1.5 \mathrm{ppbv}$. When a scrubber is used, values between impinger and cartridge are better correlated.

\section{Conclusion}

This study has shown that the 2,4-DNPH method used for atmospheric sampling of carbonyls is not without difficulties as some interferences have been pointed out for ozone and humidity. Ozone can react with the formed hydrazone and the 2,4-DNPH. Humidity can be a serious problem for ketone measurement. The comparison between impinger and cartridge has shown that except for acetaldehyde and benzaldehyde, the two techniques do not give coherent results. When no ozone scrubber is used, the cartridge technique gives systematically lower values.

Bad correlation has been obtained between data with scrubber and data without scrubber for the impinger technique except for acetaldehyde. For the cartridge technique, the correlation is better for all the aldehydes but higher values are found when a scrubber is used except for formaldehyde.

For the measurements in the atmospheric environment, particularly in non-polluted areas, the impinger method, with its better detection limit gives better measurements reliability. As it ensures an easier handling, especially for the samples transport from study site to the laboratory, we could prefer the method with cartridges. But in this case, three precautions should be imperatively taken in order to obtain reliable results: blank variance determination by the test of several cartridges (about 5 per box), good set cartridges selection (low $\sigma$ ), ozone scrubber use. Further investigations must be conducted in order to confirm these results. The influence of $\mathrm{NO} / \mathrm{NO}_{x}$ should also be studied. Field investigations comparing both sampling techniques must be driven with the control of different parameters such as ozone, $\mathrm{NO}_{x}$, hydrocarbon concentrations, humidity and solar irradiation. With all these data, it will be possible to give a real conclusion on the choice of one of these two techniques.

\section{References}

1. Wayne, R. P., Chemistry of Atmosphere, Clarendon Press, Oxford, 1985.

2. Finlayson-Pitts, B. J.; Pitts, J. N. Atmospheric chemistry, John Wiley and sons, New York, 1986.

3. Warnek, P. Chemistry of the natural atmosphere, Academic Press, Inc. San Diego, 1988.

4. Ferrari, C. P.; Kaluzny, P.; Roche, A.; Jacob, V.; Foster, P. Chemosphere 1998, 37, 1587-1601.

5. Kesselmeier, J.; Bode, K.; Hofmann, U.; Müller, H.; Shäfer; Wolf, A.; Ciccioli, P.; Brancaleoni, E.; Cecinato, A.; Frattoni, M.; Foster, P.; Ferrari, C.; Jacob, V.; Fugit, J. L.; Dutaur, L.; Simon, V.; Torres, L. Atmos. Environ. 1997, 31, 119-133.

6. Atkinson, R. J. Phys. Chem. Ref. Data. 1989, Monograph 1.

7. Winer, A. M. Air Pollution Chemistry, in: Handbook of Air pollution Analysis, $2^{\text {nd }}$ Edition, Harrison, R. M. \& Perry, R. Eds., Chap. 3, Chapman and Hall, London, 1985.

8. Altshuller, A. P. Atmos. Environ. 1993, 27A, 21-32.

9. Satsumabayashi, H.; Kurita, H.; Chang, Y-S.; Carmichael, R. Atmos. Environ 1995, 29, 255-266.

10. Possanzini, M.; Di Palo, V.; Petricca, M.; Fratarcangeli, R.; Brocco, D. Atmos. Environ. 1996, 30, 3757-3764.

11. Carlier, P.; Hannichi, H.; Mouvier, G. Atmos. Environ. 1986, 20, 2079-2099.

12. Slemr, J. Fres. J. Anal. Chem. 1991, 340, 672-677. 


\section{Original articles}

13. Vairavamurthy, A.; Roberts, J. M.; Newman, L. Atmos. Environ. 1992, 26A, 1965-1993.

14. Tuazon, E. C.; Graham, R. A.; Winer, A. M.; Easton, R. R.; Pitts, J. N.; Hanst, P. L. Atmos. Environ. 1978, 12, 865-875.

15. Tuazon, E. C.; Winer, A. M.; Graham, R. A.; Pitts, J. N. Jr. In Adv. Environ. Sci. Technol., Pitts, J. N.; Metclaf, R. L., 1980, 10, 865-875.

16. Platt, U.; Perner, D; Pätz, H. W. J. Geophys. Res. 1979, 84C, 6329-6335.

17. Kotzias, D.; Duane, M.; Nicollin, B. Fresenius. Env. Bull. 1992, 1, 79-83.

18. Foster, P.; Ferrari, C.; Jacob, V.; Roche, A.; Baussand, P.; Delachaume, J. C. Analusis 1996, 24, 71-73.

19. Altshuller, A. P.; Miller, D. L.; Sleva, S. F. Anal. Chem. 1961 33, 621-625.

20. Chiavari, G.; Lagui, M. C.; Torsi, G. J. Chromatog. 1989, 475, 343-351.
21. Yokouchi, Y.; Mukai, H.; Nakajima, K.; Ambe, Y. Atmos. Environ. 1990, 24, 439-442.

22. Foster, P.; Dehaudt, P.; Besson, J. Pollution Atmosphérique 1984, 245.

23. Arnst, R. R.; Tejada, S. B. Environ. Sci. Technol. 1989, 23, 1428-1430.

24. Atkinson, R.; Carter, W. P. L. Chem. Rev. 1984, 84, 437-439.

25. Smith, D. F.; Kleindienst, T. E.; Hudgens, E. E. J. Chromatog. 1989, 483, 431-436.

26. Kalabokas, P. Thèse de doctorat, Étude des facteurs sources et puits des composés carbonylés dans les masses d'air transitant au-dessus de la région parisienne, 1987, Paris.

27. Waters Sep Pack DNPH-Silica cartridges care and use manual. Waters, 34, Mapple street, Milford MA, 01757, Appendix $\mathrm{C}$ (Making an ozone scrubber).

28. Lipari, F.; Swarin, S.J. Environ. Sci. Technol. 1985, 19, 70-74. 